Research Paper

\title{
Bladder Reconstruction with Human Amniotic Membrane in a Xenograft Rat Model: A Preclinical Study
}

\author{
Dimitri Barski ${ }^{\boxplus}$, Holger Gerullis², Thorsten Ecke³ , Jin Yang", Gabriella Varga ${ }^{5}$, Mihaly Boros ${ }^{5}$, Isabel \\ Pintelon $^{6}$, Jean-Pierre Timmermans ${ }^{6}$, Thomas Otto ${ }^{1}$ \\ 1. Department of Urology, Lukas Hospital Neuss, Germany; \\ 2. University Hospital for Urology, School of Medicine and Health Sciences, Carl von Ossietzky University, Oldenburg, Germany; \\ 3. Department of Urology, Helios Hospital, Bad Saarow, Germany. \\ 4. Department of Urology, Affiliated Hospital of Chengdu University, Chengdu, China. \\ 5. Institute of Experimental Surgery, University of Szeged, Hungary. \\ 6. University of Antwerp, Laboratory of Cell Biology and Histology, Antwerp, Belgium. \\ $\square$ Corresponding author: Lukas Hospital, Neuss, Preussenstr. 84, 41464 Neuss, Germany, Tel. 0049-2131-8882401, Fax 0049-2131-8882499, Email: \\ dbarski@lukasneuss.de.
}

(c) Ivyspring International Publisher. This is an open access article distributed under the terms of the Creative Commons Attribution (CC BY-NC) license (https:// creativecommons.org/licenses/by-nc/4.0/). See http://ivyspring.com/terms for full terms and conditions.

Received: 2016.10.28; Accepted: 2017.01.30; Published: 2017.03.11

\begin{abstract}
Background: Human amniotic membranes (HAMs) are assumed to have a number of unique characteristics including durability, hypoallergenic and anti-inflammatory properties.

Materials and Methods: Multilayer HAMs from caesarian sections were applied to repair defined bladder defects in male Sprague-Dawley rats. The animals were sacrificed at 7, 21 and 42 days after implantation. Bladder volume capacity after grafting was measured. Histological analyses were performed to asses a number of parameters including HAM degradation, inflammatory reaction, graft rejection and smooth muscle ingrowth.

Results: One rat died from sepsis in the treated group. No severe complications or signs of leakage were observed. Bladder capacity did not change over time. The initially increased inflammation in the HAM group diminished significantly over time $(p<0.05)$. No signs of HAM degradation were observed and smooth muscle staining increased over time.

Conclusions: HAMs appear to be durable and hypoallergenic grafts. The assumed suitability for the reconstruction of urinary tract justifies further research on detailed immunological process in larger grafts.
\end{abstract}

Key words: amniotic membrane, bladder augmentation, graft, rat experiment, IDEAL.

\section{Introduction}

Defects of urinary tract can be caused by a multitude of complications and events, such as catheterization-related urethral and ureteral strictures, surgery, stone passage or infections or fistulas. Preservation of continence and social autonomy after oncological surgery or radiation are gaining importance. One of the major reconstructive problems relates to lack of healthy native tissue for repair in patients, who have received multiple radiation treatments or undergone multiple surgeries. Autolog, xenolog and synthetic materials have been tested for the reconstruction of urinary tract defects, but these experiments have not yielded any sustainable results for a number of reasons, including degradation, rejection or inflammation of the graft or scarring due to reduced perfusion.

New scaffolds and biomaterials are needed to achieve a fast regeneration without adverse effects. At present, four different approaches are applied: synthetic polymers (polyglycolic- (PGA), polylactic acid (PLA)), biologically derived materials (bladder acellular matrix), cell-based tissue engineering and composite materials [1]. Synthetic materials are available but cause additional complications and 
serious concerns have recently been raised about the use of alloplastic materials in the pelvic floor [2]. The composite scaffolds were fabricated by binding collagen with PGA. Advances in tissue engineering technology have enabled seeding of scaffolds with autologous bladder epithelial and smooth muscle cells. Several experimental and clinical pilot studies have shown the potential of neo-bladder formation with a structure that is similar to that of native bladder tissue. For instance, improved bladder capacity was seen in seven patients with myelomeningocele following cystoplasty with engineered bladder tissue [3]. A prospective multicenter phase II trial from USA used a similar cell-seeded bio-degradable collagen scaffold for bladder augmentation in children and adolescents with spina bifida ( $n=11$, follow up $36 \mathrm{mos}$ ), but no improved bladder capacity or bladder compliance were observed, while several serious adverse events occurred [4]. Another strategy consists in applying naturally derived acellular matrices, such as small intestinal submucosa (SIS) or bladder acellular matrix (BAM), in an attempt to induce a native cell seeding of urothelial and smooth muscle cells from the neighboring native bladder tissue or ureters. Several experimental trials with rat, dog, sheep and porcine models have reported promising short-term results over the last two decades. However, the main problems are fibrosis and graft shrinkage of the large scaffolds, along with fast degradation, the need for immune therapy and the insufficient cell seeding due to a lack of tissue growth factors [5-9]. An Italian group augmented the bladders of five patients with exstrophic bladders using a SIS scaffold and included a long-term follow-up period of 3 years. After 6 months there was no histological evidence of SIS with feasible regeneration. However, poor results were obtained in terms of muscle regeneration, bladder capacity and continence [10]. Correct muscle alignment, proper innervation and vascularization are crucial for the development of larger contractile tissues that allow physiological voiding. Current research efforts in many centers are aimed at developing 'smart', biologically active biomaterials that improve tissue regeneration [11].

We hypothesized that the regeneration of important bladder wall components, such as urothelium, vascularization and smooth muscle, can be improved by application of hypoallergenic HAMs containing multiple growth factors. Outcomes of reconstruction of an experimental bladder defect using this scaffold were compared with outcomes in a group that was repaired with suture only. Following the evolving IDEAL-Device (Idea, Development, Evaluation, Assessment and Longterm) framework for evaluation and regulation of surgical innovations, we established a preclinical xenograft model to provide evidence that HAMs are instrumental in repairing bladder defects. These experiments can be categorized as a stage 0 preclinical study for the evaluation of a new medical product according to IDEAL-D $[12,13]$.

\section{Materials and Methods}

\section{Human amniotic membrane (HAM)}

HAMs were obtained immediately after elective cesarean sections with normal gestation and informed consent of the patients. Ethical permission was obtained from the local ethics committee, University of Szeged. The study has been conducted according to the principles expressed in the Declaration of Helsinki. The donors were screened for infections including HIV, hepatitis and syphilis. The placenta was cleaned of blood clots with sterile phosphate-buffered saline (PBS) and the amnion was separated from the chorion by blunt dissection under the laminar flow. The separated membranes were cut into segments of at least $5 \times 5 \mathrm{~cm}^{2}$ with the epithelial side up. After several rinsing steps the HAMs were frozen at $-20^{\circ} \mathrm{C}$ for 24 hours until further use. For further processing, the HAMs were defrosted in water, sterilized in peracetic acid and alcohol mixture, and incubated for 2 hours on the shaker. After rinsing the HAMs were prepared in four layers applied on a sterile silicon scaffold and dried under laminar flow (Fig. 1).

\section{Experimental animals}

The animal experiment was conducted at the Institute for Experimental Surgery of the University of Szeged, Hungary, in accordance with the National Institutes of Health guidelines (Guide for the Care and Use of Laboratory Animals). The experimental protocol was approved by the Animal Welfare Committee at the University of Szeged (license number V./146/2013). The experiments were performed according to the EU Directive 2010/63/EU on the protection of animals used for experimental and other scientific purposes and carried out in strict adherence to the NIH guidelines for the use of experimental animals. The study was approved by the National Scientific Ethical Committee on Animal Experimentation (National Competent Authority).

Twenty-seven male Sprague-Dawley rats, weighing from 320 to $380 \mathrm{~g}$ and 3 months old, were housed and cared for at Szeged University's farm for experimental animal studies. All animals had free access to food and water and were cared for by an educated keeper and routinely inspected by a veterinarian. 


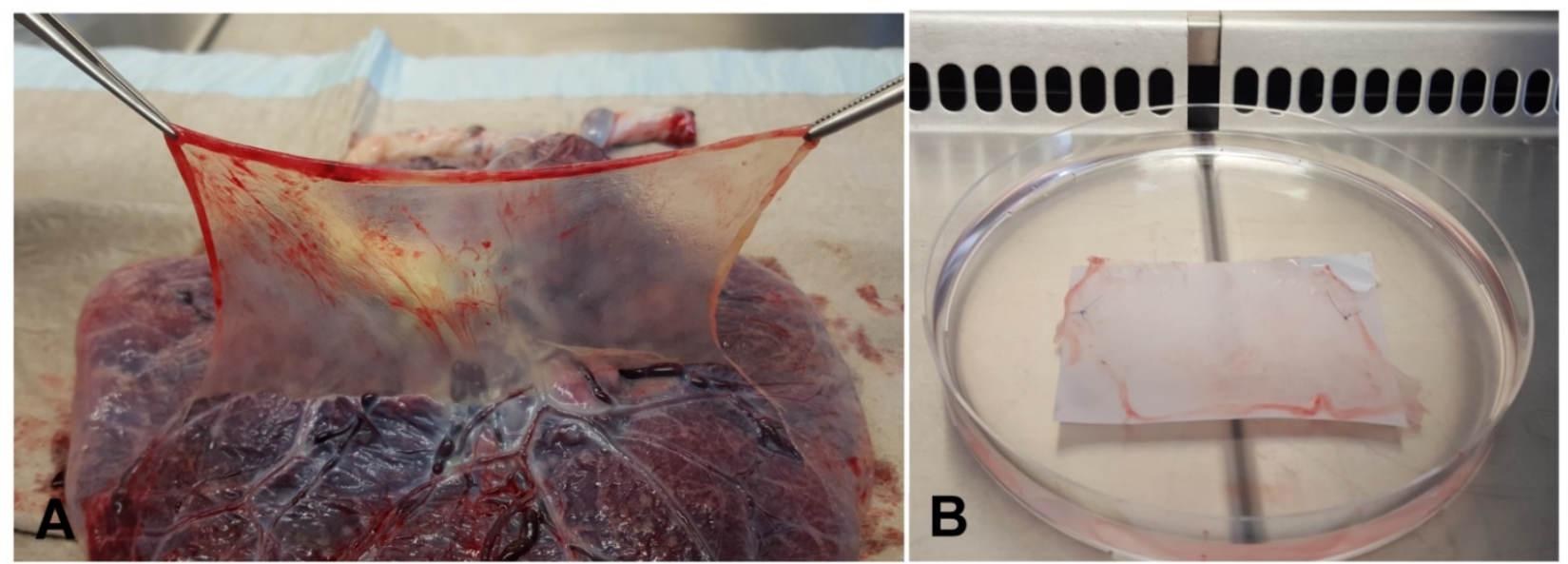

Figure 1. A. Preparation of amniotic membrane with dissection from the chorion under laminar flow. B. Dried and cryopreserved multilayered amniotic membrane graft.

\section{Operation procedure}

The procedures were performed by two surgeons (DB and HG) using sterile surgical techniques. Sprague-Dawley rats were anesthetized with $40 \mathrm{mg} / \mathrm{kg}$ of ketamine $10 \%$. The abdomen was shaved and prepared with an ethanol-propanol solution. Rats were operated in supine position. A microscope and microsurgical instruments were used. A midline laparotomy was performed. The bladder was identified and bladder capacity was determined $(\mathrm{ml})$ before grafting in a standardized way. Evaluation of bladder pressure was performed via a cystometric method adapted from Lundbeck et al. [14]. After the dome of the bladder was exposed a 20 gauge needle was inserted through a small puncture in the dome of the bladder and secured in the place by a clamp. The bladder was emptied by a syringe. The needle was attached to an infusion system at $20 \mathrm{~cm}$ height above the bladder. Room temperature saline was infused by gravity and the bladder capacity was measured at the timepoint of infusion stop. The bladder was emptied, the procedure repeated two additional times, and the mean value recorded. Subsequently, the defined 0.5 $\mathrm{cm}$ lesion was cut at the bladder dome. In the treated amnion group $(\mathrm{A}, \mathrm{n}=18)$ a multilayer amnion patch was trimmed overlapping the defect size $(10 \times 10 \mathrm{~mm})$ and fixed to the bladder wall with 6-0 monocryl (Ethicon, Norderstedt, Germany) single sutures at three to four points. Additionaly human fibrin glue (Evicel, OMRIX Biopharmaceuticals Ltd, Israel) was used to seal the lesion. In the first control group $(\mathrm{C} 1$, $n=6$ ) the defect was closed with a single monocryl 6-0 running suture and fibrin glue. In the second control group $(\mathrm{C} 2, \mathrm{n}=3)$ the amnion graft was sutured to the bladder wall without prior lesion. Fluid loss was compensated by administering $3 \mathrm{ml}$ of $0.9 \%$ saline intraperitoneally at the end of surgery. Subsequently, the abdominal fascia and skin were closed in layers with absorbable Vicryl 5-0 running suture and Monocryl 4-0 interrupted suture (Ethicon, Norderstedt, Germany).

The animals were sacrificed at one $(A, n=5 ; C 1$, $\mathrm{n}=2 ; \mathrm{C} 2, \mathrm{n}=1)$, three $(\mathrm{A}, \mathrm{n}=6 ; \mathrm{C} 1, \mathrm{n}=2 ; \mathrm{C} 2, \mathrm{n}=1)$ and six $(A, n=5 ; C 1, n=2 ; C 2, n=1)$ weeks after surgery. Bladder capacity was determined again. Subsequently, urinary bladder and tissue samples (urinary bladder, kidneys, spleen) were harvested and stored in $10 \%$ formalin solution for 2 hours and then stored in PBS at $4^{\circ} \mathrm{C}$.

\section{Clinical Assessment}

Grafts and bladder wall were assessed regarding color, tissue contraction, inflammation and pliability by two surgeons (D.B. and H.G.). Results were documented by photograph.

\section{Histology and Immunohistochemistry}

All specimens were fixed and embedded in paraffin wax. Deparaffinized sections $(5 \mu \mathrm{m})$ were used for staining with Hematoxylin and Eosin (H\&E) to visualise tissue architecture and cell infiltration. Immunohistochemical staining was performed using an antibody against alpha-smooth muscle actin (a-actin; A2547; Sigma-Aldrich, Bornem, Belgium) to confirm the presence of smooth muscle fibres. Tissue sections were deparaffinized, rehydrated and subjected to a heat-induced antigen retrieval (Citrate Buffer, $\mathrm{pH}$ 6.0), followed by $3 \%$ hydrogen peroxide and avidin-biotin blocking. Prior to incubation with the primary antiserum, sections were incubated with PBS blocking solution containing $10 \%$ normal horse serum, $0.1 \%$ bovine serum albumin, $0.05 \%$ thimerosal, $0.01 \% \mathrm{NaN}_{3}$ and $1 \%$ Triton X-100. Primary and secondary antiserum were diluted in blocking solution without Triton X-100. Sections were 
incubated overnight with the primary antibody and immunostained with streptavidin-biotin-peroxidase method, followed by diaminobenzidine (DAB) chromogen solution. Finally, sections were counterstained with hematoxylin and mounted in xylene-based mountant. Negative controls were incubated in blocking solution without primary antibodies. Pictures were taken using an Zeiss Axiophot microscope (Zeiss, Jena, Germany) equiped with an Olympus DP70 digital camera (Olympus, Münster, Germany) at 4x magnification.

Particular attention was paid to the slides showing the transition zone between the amnion graft and normal bladder wall. Semi-quantitative scores from 0 to 3 for inflammation were used. Inflammation of the implant region was scored by counting lymphocytes in 10 fields of $0.25 \mathrm{~mm}^{2}$ in three observer-randomized $\mathrm{H} \& \mathrm{E}$ slides (semi-quantitative score: $0=<5 \%$ cells $/$ field; $1=5-25 \% ; 2=25-50 \% ; 3=$ $>50 \%$; 200x magnification). AM-thickness was measured in $\mu \mathrm{m}$ to assess degradation and inflammation. Kindneys and spleen specimen were analysed for signs of transplant rejection.

\section{Statistical analysis}

The data were documented into Microsoft Excel software and then transferred into a GraphPadPrism6.0 (Graphpad Software, Inc.) data bank for statistical analysis. Continuous data were checked for normality of distribution before choosing between parametric and non-parametric tests. The results were presented as medians with range or means with standard deviation (SD) in case of normal distribution. Data from different groups were compared using the Mann-Whitney $U$ test and the Kruskal-Wallis test. Statistical significance was assumed at $\mathrm{p}<0.05$.

\section{Results}

\section{Clinical course and functional results}

Two animals (11\%) died in the treated group (A), one animal due to postoperative sepsis and another animal during anesthesia, respectively. No animals from the control groups $\mathrm{C} 1$ and $\mathrm{C} 2$ died. No other severe complications higher than grade II (Clavien-Dindo classification) were observed. The bladder capacity did not change in the treated group A but reduced significantly in the control group $\mathrm{C} 1$ with suture of the lesion ( $\mathrm{p}=0.01)$ (Fig. 2).

\section{Macroscopic examination}

\section{7 days}

No signs of severe inflammation were found in the abdominal cavity during resurgery.
Meso-adhesions to the HAM graft were detected in most treated cases. The multilayer amnion was clearly detectable as a shiny, reddish layer on the bladder wall. HAM appeared as a thick, edematous graft with inflammation running from the middle towards the transition zone of the bladder wall. Blister formation was seen in one case. Inflammation was less prominent in the control groups ( $\mathrm{C} 1$ and $\mathrm{C} 2)$.

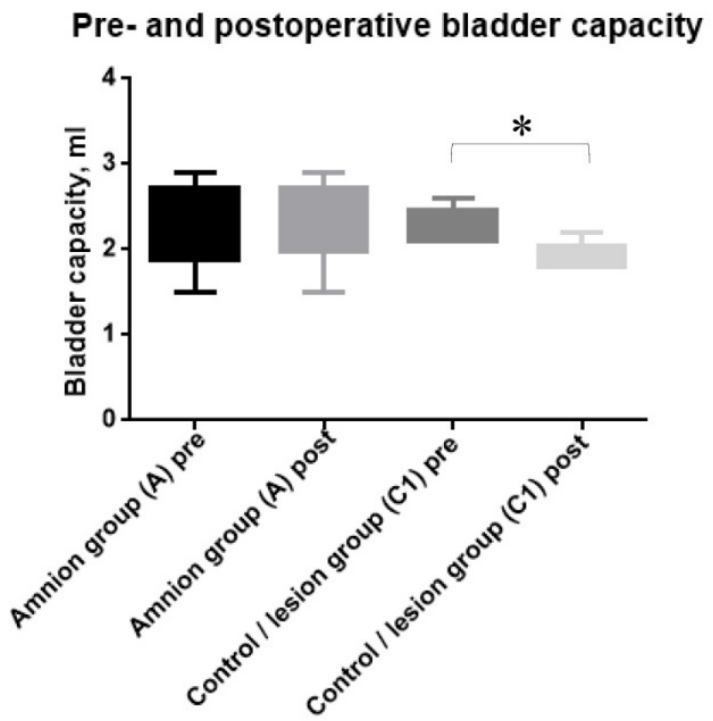

Figure 2. Bladder capacity pre- and postoperatively in the amnion treated group $\mathrm{A}$ and control group $\mathrm{Cl}$. The bladder capacity reduced significantly in the control group due to the scaring of the sutured lesion $(* p<0.05)$

\section{1 days}

HAM was still well defined, albeit with reduced inflammation. The edema had almost disappeared and the amnion graft appeared as a reddish layer on the bladder wall (Fig. 3). Adhesions were still present in some cases.

42 days

HAM was still recognizable, but the colour had changed to a whitish-grey with signs of inflammation and blood vessels formation in the transition zone of the bladder wall (Fig. 3).

\section{Microscopic examination}

7 days

The xenotransplanted HAM graft covered the bladder wall and maintained its architecture in the treated group. The lesions could be recognized as the regions without smooth muscle cells but with abundant connective tissue and signs of inflammation. Significant inflammation and increased blood vessels numbers were observed in the amnion and between the amnion and the adventitia of the bladder, which resulted in an enlarged amnion. 
Infiltrated lymphocytes agglomerated mostly in the area bordering the HAM. No shrinkage of the transplanted grafts was seen in any of the specimens.
Lower inflammation levels were found in the control groups $\mathrm{C} 1$ and $\mathrm{C} 2$ (Fig. 4).
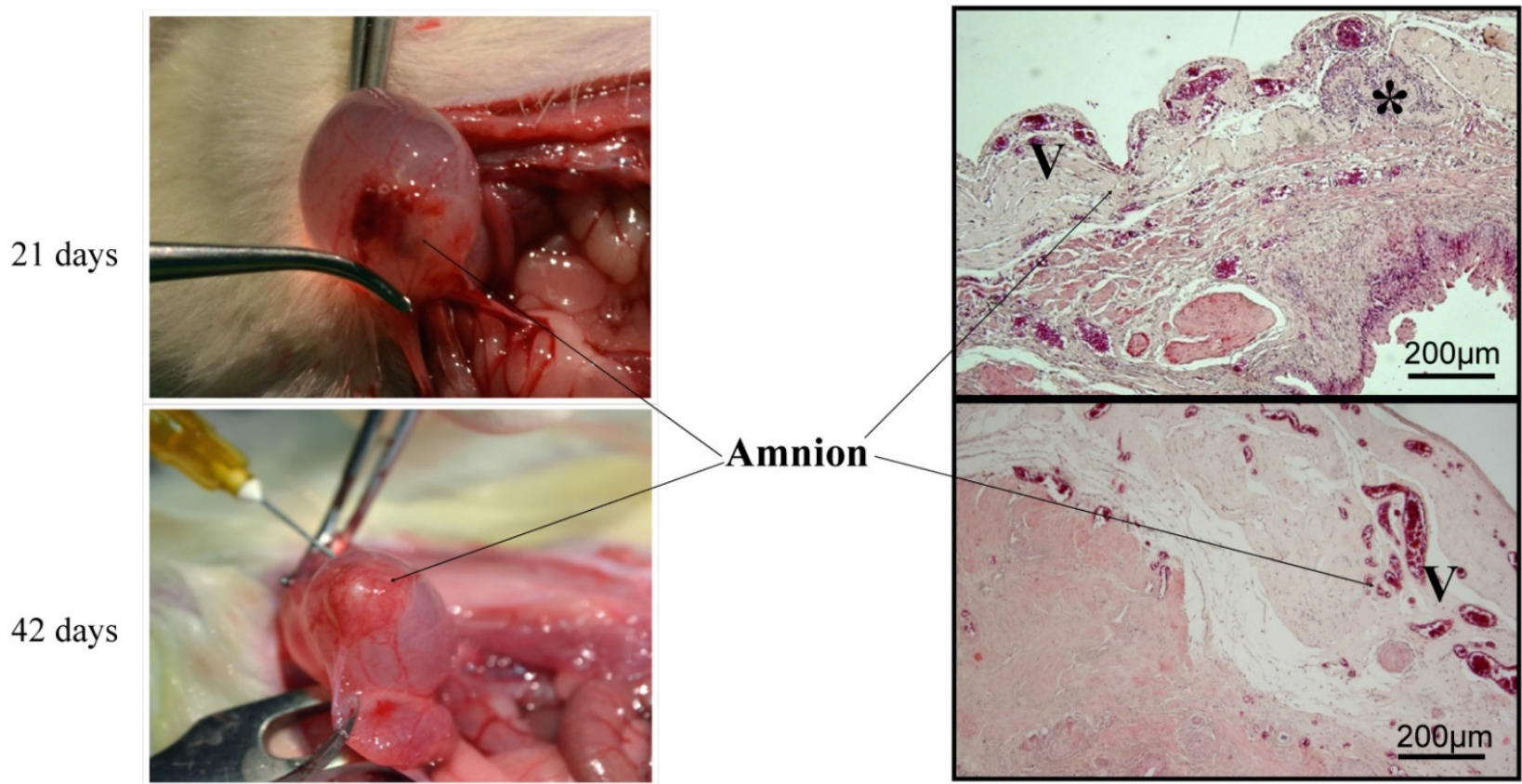

Figure 3. Macroscopic and histological evaluation (H\&E staining) of inflammation and AM degradation over time (21 and 42 days after grafting). Reduction of inflammation over time. Decreased inflammatory cells $\left(^{*}\right)$ and increased vascularization $(\mathrm{V})$ in the periamniotic transition zone were detected. No signs of AM degradation. Scale bar $200 \mu \mathrm{m}$.

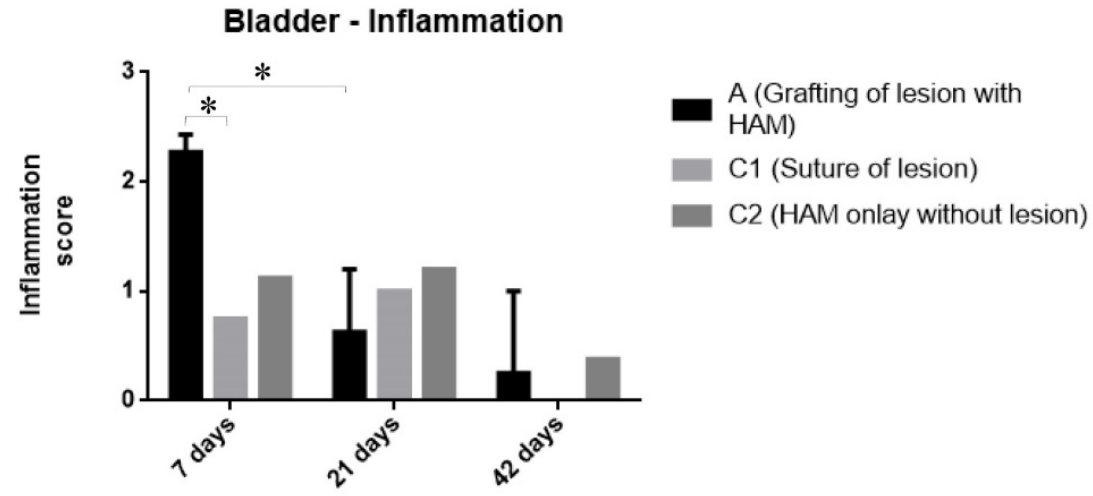

Figure 4. Reduction of inflammation over time, semiquantative analyses of inflammatory cells: Treated (A): Amnion repair of bladder defect. Control/Lesion (C1): Closure of bladder defect with suture. Control/Amnion (C2): Amnion bladder onlay without defect. Semi-quantitative score: $0=<5 \%$ cells/field; $1=5-25 \% ; 2=$ $25-50 \% ; 3=>50 \%$; $200 x$ magnification. Data is expressed as median with range. *, significant reduction $(p<0.05)$.

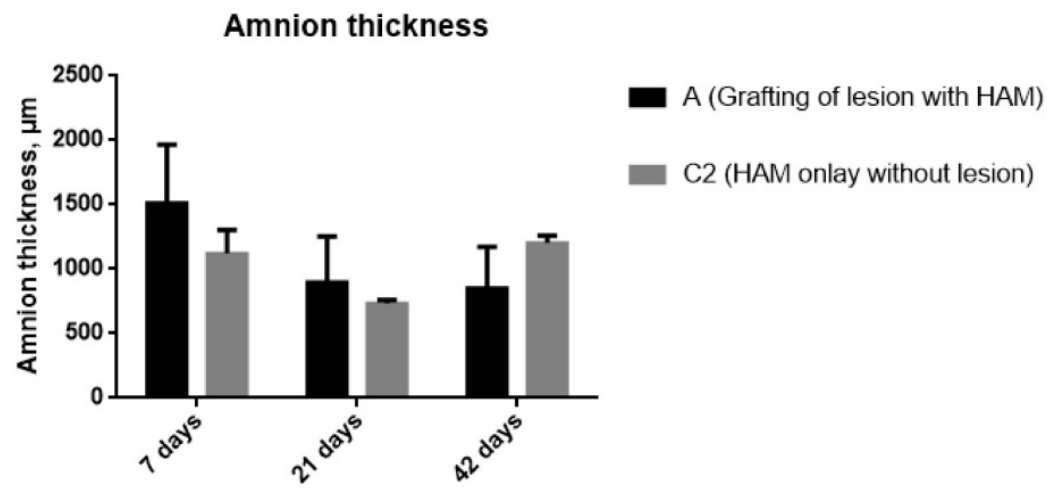

Figure 5. Measurement of amnion thickness over time (7, 21 and 42 days): Treated (A): Amnion repair of bladder defect. Control/Amnion (C2): Amnion bladder onlay without defect. Data is expressed as mean with $\mathrm{SD}, \mathrm{p}<0.05$. 

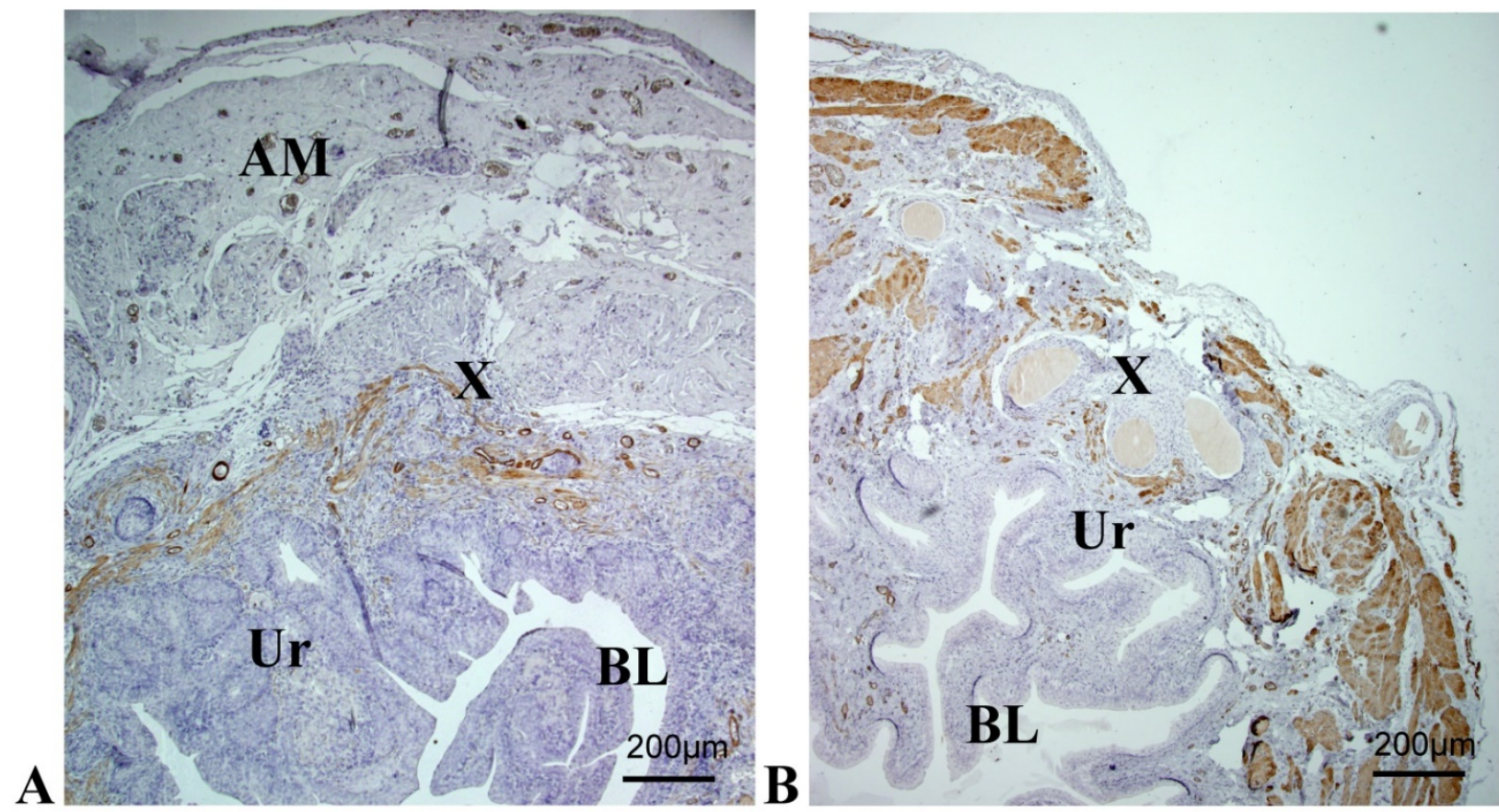

Figure 6. Immunohistological analysis of a reconstructed urinary bladder wall at timepoint 3 (42 days). A: Amnion group, reconstruction with AM graft; B: Control group, reconstruction with suture, AM; Amniotic membrane, Ur; Urothelium, BL; lumen of urinary bladder, $\mathrm{X}$; region of lesion in the bladder wall. (A) H\&E staining displaying mild inflammatory infiltration. $\alpha$-Actin staining reveals frequently arranged smooth muscle bundles (arrows). Strong immunoreactivity underneath the urothelium layer is observed. The region of the lesion can be clearly recognized in the control group with muscle bundles, while there is a smooth muscle ingrowth in the treated group.

\section{1 days}

The amnion including its different layers was mostly still clearly recognizable. No signs of amnion degradation or necrosis were observed, but the amnion appeared less thick compared to time point 1 (Fig. 5). Inflammation of the amnion was significantly diminished $(p<0.05)$ (Fig. 3, Fig. 4 and Fig. 6). However, a moderate number of lymphocytes and a few eosinophils were detected in the transition zone between the graft and the surroundig tissue. New capillaries started to grow into the surrounding connective tissues and scattered smooth muscle cells appeared in the area of the lesion. In the control groups $\mathrm{C} 1$ and $\mathrm{C} 2$ signs of inflammations (presence of lymphocytes) had mostly disappeared and the differences were less obvious. More connective tissue with scattered smooth muscle cells was discerned (Fig. 3).

\section{2 days}

It has become more difficult to discriminate the region of the lesion in the treated group, where the amnion formed a thinner layer on the bladder wall with no signs of degradation (Figures 3 and 5). Inflammation was markedly reduced in the amnion and in the zone between the amnion and the bladder wall $(p<0.05)$ (Figures 3 and 4$)$. The number of large vessels in the amnion appeared to be reduced and periamniotic vascularization increased but these results were not significant. Connective tissue, bundles and thin muscle layers were abundantly found in all groups. Smooth muscle regeneration appeared faster in the treated group (Fig. 6), although the difference in the regeneration compared to the control group with suture of the lesion was not significant $(\mathrm{p}<0.05)$.

\section{Rejection}

No macroscopic signs of rejection were found in the kidney or spleen specimens. However, 4 out of 6 animals in the treated group showed an affected kidney at time point 2 . The changes were subtle with slightly enlarged tubuli and urinary space. The glomeruli appeared denser. No immune cells or other signs of transplant rejection were observed. At time point 3 , only the kidneys of 2 of the 5 animals were still slightly affected, while no such alterations were detected in the controls without amnion had no such alterations. To exclude an obstruction or increased bladder pressure due to the HAM graft as the cause for these findings, we compared the results with another study, where we used amnion graft on colon (unpublished data). The same alterations were detected in the kidneys in this group. Taken together, a subtle, transient transplant glomerulitis is suggested in case of HAM graft in a rat. 


\section{Discussion}

The aim of our study was to assess the functional, inflammatory and allergenic characteristics of human amniotic membrane in a xenograft rat model.

HAMs have been widely used for decades in ophthalmic surgery, mainly to cover defects after corneal ulcerations $[15,16]$. Today, HAM grafts are considered the standard therapy to reconstruct the eye surface as shown in several randomized and controlled trials $[17,18]$. The effectiveness of HAMs has been amply demonstrated in several clinical studies, for instance, as skin graft donor site dressing in burn patients or for the reconstruction of dental defects and oro-pharyngeal fistulas [19-22]. Furthermore, tissue-engineered HAMs have been used as matrix for cell seeding and expansion of epithelial progenitor cells in ophthalmology, orthopedics, healing of liver dysfunction, etc. [23, 24].

Currently there is a growing interest in extending the application possibilities of HAMs due to their wide availability, low costs and interesting properties. The technique of applying HAMs in reconstructive urology was introduced for the first time in 1955 although only a few groups applied AM to repair the urinary tract wall [25]. Reconstruction of urethrae with HAMs in a rabbit model showed a proper re-epithelialization, and even better results could be achieved with a denuded human amniotic scaffold inoculated with primary rabbit urethral epithelial cells [26, 27]. A Polish group described a technique to supplement long ureteral wall strictures $(5.5 \mathrm{~cm})$ by using folded HAM allografts and presented good, sustainable results after an average follow-up period of 25.2 months [28]. Brandt and coworkers successfully reconstructed a female urethra using autologous grafts prepared from HAMs [29]. Reconstruction of a complex vesico-vaginal fistula with a HAM interposition patch was shown in two case reports [30, 31]. Excellent integration of the implanted amnion graft within the host urinary tract wall and reduced fibrosis were reported after the reconstructive procedures. Adamowicz and coworkers designed a sandwich-structured biocomposite material from a frozen cell-seeded (bone marrow-derived mesenchymal stem cells) HAM and covered it on both sides with two-layered membranes prepared from electrospun poly-(L-lactide-coecaprolactone) (PLCL). The authors considered this reinforcement of the AM necessary because of its poor mechanical qualities. The new biomaterial (10x10 $\mathrm{mm}$ ) was used for bladder augmentation after hemicystectomy in 10 rats, which were sacrificed after 3 months [32]. Immunohistohemical analysis revealed effective regeneration of the urothelial and smooth muscle cells and complete PLCL degradation. However, the authors reported a moderate inflammatory reaction after 3 months.

In contrast, the results of our study confirm previous reports in which the elasticity and durability of multilayer HAMs were described and no signs of leakage and unchanged bladder capacity were observed after the reconstruction. A modified "simple cystometry" by infusion of flood by gravity at a pressure head of $20 \mathrm{~cm}$ was used in our experiments, sensitivity comparable to standard multichannel cystometry [33]. The cystometric results were highly reproducible on repeated assessments, confirming the reliability of this procedure to assess the bladder capacity in the rat model. The differences in bladder volume change were only about $<15 \%$ of the total volume, due to a small defect. More obvious reduction of bladder capacity is known from patients with partial bladder resection with the need for augmentation surgery. Future studies with larger grafts are planned.

The inflammatory reaction had almost disappeared already after 6 weeks. The mechanical behavior of the urinary bladder is dependent on the properties of the extracellular matrix and smooth muscle cells. The extracellular matrix (ECM) of HAMs is composed of collagen (type I, III, IV, V and VI), fibronectin, nidogen, laminin, proteoglycans and hyaluronan in a proportion that is similar to the basement membrane of urinary tracts [34]. With a diameter of about 150 - $200 \mathrm{~nm}$ amniotic membrane is one of the thickest membranes of the human body and its stroma provides elasticity and mechanical strain. Large grafts need sufficient nutrition of the cells and removal of waste products to eliminate/reduce the risk of fibrosis and shrinkage. Having a diffusion distance from the supplying blood vessel of $~ 150-200$ $\mu \mathrm{m}$, HAMs efficiently conduct sufficient oxygenation of cells by diffusion [35]. No signs of graft shrinkage or necrosis were found during the 6-wk follow-up period.

The limitations of our study were the small size of the grafts $(10 \times 10 \mathrm{~mm})$, missing detailed data on immunological process of regeneration and the short follow-up period. Regeneration in large constructs or even neo-bladder needs further evaluation. Multiple soluble active growth factors have been identified within cryopreserved HAMs [36]. This naturally derived composition of incorporated growth factors is predisposed to support fetal healing - rapidly and without an inflammatory response - resulting in a complete restitution of normal tissue function [37]. HAMs secrete the glycoprotein lumican and growth factors like epidermal growth factor (EGF), a hepatocyte growth factor (HGF) and keratinocyte 
growth factor (KGF), which stimulate epithelial cell growth [36]. Wound healing is a highly complex process of inflammation, regeneration of tissue, angiogenesis, scarring and reepithelialization. Amnion was previously described to reduce the scar tissue building by the inhibition of fibroblasts. There is no scarring after the child injuries in the amniotic sac. Kim and Tseng transplanted HAM for surface reconstruction of cornea in vitro and in animal studies [15]. They detected reduced fibroblast building by suppression of Transforming growth factor-B (TGF- $B$ ). Further studies confirmed that amniotic stroma includes factors which inhibit the proliferation of myofibroblasts [38]. The results of the presented study support the hypothesis of faster tissue regeneration by inhibition of scar building. However, a detailed immunohistological investigation of regeneration process in larger grafts would be a part of the future work to be done. Although we expected a faster regeneration of smooth muscle in the amnion group due to the presence of growth factors, our results were not significant in this respect and it was not possible to compare the regeneration in a standardized way due to the small size of the grafts used and an overlap with the normal bladder wall.

The overall low complication rate was comparable to previous reports [26-32]. One animal in the treated group $(5.6 \%)$ died due to sepsis. All animals in the amnion group presented a transient local inflammation and the amnion group included several cases of local abdominal adhesions, but no signs of peritonitis. Akle and Adolfini detected no signs of acute rejection after allogen subcutaneously implanted HAMs [39]. Fas ligand positive cells, suppression of TGF- $\beta$ are other examples for immunological privilege of the amniotic membrane. The marked edema in the first week and high inflammation score in the amnion graft group may reflect the local immunological rejection in the presented study. However, this reaction is transient and no differences between the groups were found in follow up. A similar transient increase in inflammatory cells was reported by Kesting et al., who used cryopreserved HAMs for soft tissue repair in rats [40]. Additionally, most animals of the amnion group presented a subtle acellular transplant glomerulitis. These changes can be classified as borderline mild acute rejection according to the Banff classification [41]. However, due to the relatively short follow-up period, it was not possible to determine whether chronic glomerulitis with interstitial fibrosis and tubular atrophy would develop. Still, 2 of 5 animals were slightly affected in the amnion group. We suggest that the glomerulitis observed during our experiments was due to the xenolog model and that glomerulitis would normally not develop in an allogen human setting. However, further studies on immunological process are needed to confirm this assumption.

We suggest that HAMs are appropriate for the reconstruction of small defects (fistula grafting, urethro- and ureteroplasty), but not of the whole organ, which requires healthy tissue ingrowth. Experiments with larger scaffolds need to be conducted to further explore the clinical potential of HAMs. Following the IDEAL-D recommendations, further evaluation of possible indications in clinical studies is needed after successful stage 0 experimental results.

\section{Conclusions}

Preclinical xenotransplantation model supports the application of HAMs for reconstruction of urinary tract. Successful closure of defined bladder wall defects could be achieved by using multilayered HAMs. The inflammation and rejection were subtle and transient and smooth muscle ingrowth appeared to be enhanced. These findings need further support by research in larger animals and in human allogen settings to explore immunological HAM impact and possible further applications of HAMs in reconstructive surgery.

\section{Abbreviations}

BAM: bladder acellular matrix; DAB: diaminobenzidine; ECM: extracellular matrix; EGF: epidermal growth factor; IDEAL: idea, development, evaluation, assessment and longterm evaluation; ITERA: International Tissue Engineering Research Association; ITERM: Institute of Tissue Engineering and Regenerative Medicine; HAM: human amniotic membrane; HGF: hepatocyte growth factor; KGF: keratinocyte growth factor; PBS: phosphate-buffered saline; PGA: polyglycolic acid; PLA: polylactic acid; SIS: small intestinal submucosa; PLCL: poly-L-lactide-co-ecaprolactone; TGF- $ß$ : transforming growth factor-1.

\section{Acknowledgements}

The authors highly appreciate the outstanding support throughout the experiments from Albert Ramon, International Tissue Engineering Research Association (ITERA), Belgium and Peter Ponsaerts, Laboratory of Experimental Hematology, University of Antwerp, Belgium. Special thanks for the laboratory support go to Annette Wiggen-Kremer, Institute of Tissue Engineering and Regenerative Medicine (ITERM), Lukas Hospital Neuss, Germany. 


\section{Competing Interests}

The authors have declared that no competing interest exists.

\section{References}

[1] Alberti C. Tissue engineering as innovative chance for organ replacement in radical tumor surgery. Eur Rev Med Pharmacol Sci. 2013;17(5):624-31.

[2] Otto T, Klosterhalfen B, Klinge U, Boros M, Ysebaert D, Williams K. Implants in urogynecology. Biomed Res Int. 2015;2015:354342.

[3] Atala A, Bauer SB, Soker S, Yoo JJ, Retik AB. Tissue-engineered autologous bladders for patients needing cystoplasty. Lancet. 2006;367(9518):1241-6.

[4] Joseph DB, Borer JG, De Filippo RE, Hodges SJ, McLorie GA. Autologous cell seeded biodegradable scaffold for augmentation cystoplasty: phase II study in children and adolescents with spina bifida. J Urol. 2014;191(5):1389-95.

[5] Probst M, Piechota HJ, Dahiya R, Tanagho EA. Homologous bladder augmentation in dog with the bladder acellular matrix graft. BJU Int. 2000;85(3):362-71.

[6] Wefer J, Sievert KD, Schlote N, Wefer AE, Nunes L, Dahiya R, et al. Time dependent smooth muscle regeneration and maturation in a bladder acellular matrix graft: histological studies and in vivo functional evaluation. J Urol. 2001;165(5):1755-9.

[7] Kikuno N, Kawamoto K, Hirata H, Vejdani K, Kawakami K, Fandel T, et al. Nerve growth factor combined with vascular endothelial growth factor enhances regeneration of bladder acellular matrix graft in spinal cord injury-induced neurogenic rat bladder. BJU Int. 2009;103(10):1424-8.

[8] Mitsui Y, Shiina H, Hiraoka T, Arichi N, Yasumoto H, Dahiya R, et al Simultaneous implantation of bilateral ureters into bladder acellular matrix graft after partial cystectomy in a porcine model. BJU Int. 2012;110(11 Pt C):E1212-7.

[9] Roelofs LA, Oosterwijk E, Kortmann BB, Daamen WF, Tiemessen DM, Brouwer KM, et al. Bladder Regeneration Using a Smart Acellular Collagen Scaffold with Growth Factors VEGF, FGF2 and HB-EGF. Tissue Eng Part A. 2016;22(1-2):83-92

[10] Caione P, Boldrini R, Salerno A, Nappo SG. Bladder augmentation using acellular collagen biomatrix: a pilot experience in exstrophic patients. Pediatr Surg Int. 2012;28(4):421-8.

[11] Horst M, Madduri S, Gobet R, Sulser T, Milleret V, Hall H, et al. Engineering functional bladder tissues. J Tissue Eng Regen Med. 2013;7(7):515-22.

[12] McCulloch P, Altman DG, Campbell WB, Flum DR, Glasziou P, Marshall JC, et al. No surgical innovation without evaluation: the IDEAL recommendations. Lancet. 2009;374(9695):1105-12.

[13] Sedrakyan A, Campbell B, Merino JG, Kuntz R, Hirst A, McCulloch P. IDEAL-D: a rational framework for evaluating and regulating the use of medical devices. BMJ. 2016;353:i2372.

[14] Lundbeck F, Djurhuus JC, Vaeth M. Bladder filling in mice: an experimental in vivo model to evaluate the reservoir function of the urinary bladder in a long term study. J Urol 1989; 141:1245-1249

[15] Kim JC, Tseng SC. Transplantation of preserved human amniotic membrane for surface reconstruction in severely damaged rabbit corneas. Cornea. 1995;14(5):473-84.

[16] Meller D, Pauklin M, Thomasen H, Westekemper H, Steuhl KP. Amniotic membrane transplantation in the human eye. Dtsch Arztebl Int. 2011;108(14):243-8.

[17] de Farias CC, Allemann N, Gomes J. Randomized Trial Comparing Amniotic Membrane Transplantation with Lamellar Corneal Graft for the Treatment of Corneal Thinning. Cornea. 2016;35(4):438-44.

[18] Abdulhalim BE, Wagih MM, Gad AA, Boghdadi G, Nagy RR. Amniotic membrane graft to conjunctival flap in treatment of non-viral resistant infectious keratitis: a randomised clinical study. $\mathrm{Br} J$ Ophthalmol. 2015;99(1):59-63.

[19] Loeffelbein DJ, Rohleder NH, Eddicks M, Baumann CM, Stoeckelhuber M, Wolff KD, et al. Evaluation of human amniotic membrane as a wound dressing for split- thickness skin-graft donor sites. Biomed Res Int. 2014;2014:572183.

[20] Kumar A, Alraiyes AH, Gildea TR. Amniotic Membrane Graft for Bronchial Anastomotic Dehiscence in a Lung Transplant Recipient. Ann Am Thorac Soc. 2015;12(10):1583-6.

[21] Rohleder NH, Loeffelbein DJ, Feistl W, Eddicks M, Wolff KD, Gulati A, et al. Repair of oronasal fistulae by interposition of multilayered amniotic membrane allograft. Plast Reconstr Surg. 2013;132(1):172-81.

[22] Salehi SH, As'adi K, Mousavi SJ, Shoar S. Evaluation of Amniotic Membrane Effectiveness in Skin Graft Donor Site Dressing in Burn Patients. Indian J Surg. 2015;77(Suppl 2):427-31.

[23] Tsai RJ, Li LM, Chen JK. Reconstruction of damaged corneas by transplantation of autologous limbal epithelial cells. $\mathrm{N}$ Engl J Med. 2000;343(2):86-93.

[24] Yuan J, Li W, Huang J, Guo X, Li X, Lu X, et al. Transplantation of human adipose stem cell-derived hepatocyte-like cells with restricted localization to liver using acellular amniotic membrane. Stem Cell Res Ther. 2015;6:217.

[25] Lenko J. [Therapy of urethral stenosis with amnion transplantation]. Pol Tyg Lek (Wars). 1955;10(34):1124-5.
[26] Shakeri S, Haghpanah A, Khezri A, Yazdani M, Monabbati A, Haghpanah S, et al. Application of amniotic membrane as xenograft for urethroplasty in rabbit. Int Urol Nephrol. 2009;41(4):895-901.

[27] Wang F, Liu T, Yang L, Zhang G, Liu H, Yi X, et al. Urethral reconstruction with tissue-engineered human amniotic scaffold in rabbit urethral injury models. Med Sci Monit. 2014;20:2430-8.

[28] Koziak A, Salagierski M, Marcheluk A, Szcześniewski R, Sosnowski M. Early experience in reconstruction of long ureteral strictures with allogenic amniotic membrane. Int J Urol. 2007;14(7):607-10.

[29] Brandt FT, Albuquerque CD, Lorenzato FR. Female urethral reconstruction with amnion grafts. Int J Surg Investig. 2000;1(5):409-14.

[30] Barski D, Gerullis H, Ecke T, Varga G, Boros M, Pintelon I, et al. Repair of a vesico-vaginal fistula with amniotic membrane - Step 1 of the IDEAL recommendations of surgical innovation. Cent European J Urol. 2015;68(4):459-61.

[31] Price DT, Price TC. Robotic repair of a vesicovaginal fistula in an irradiated field using a dehydrated amniotic allograft as an interposition patch. J Robot Surg. 2016;10(1):77-80.

[32] Adamowicz J, Pokrywczyńska M, Tworkiewicz J, Kowalczyk T, van Breda SV, Tyloch D, et al. New Amniotic Membrane Based Biocomposite for Future Application in Reconstructive Urology. PLoS One. 2016;11(1):e0146012.

[33] Wall LL, Wiskind AK and Taylor PA. Simple bladder filling with a cough stress test compared with subtracted cystometry for the diagnosis of urinary incontinence. Am J Obstet Gynecol, 1994;171: 1472,1994.

[34] Resch MD, Schlötzer-Schrehardt U, Hofmann-Rummelt C, Sauer R, Kruse FE, Beckmann MW, et al. Integration patterns of cryopreserved amniotic membranes into the human cornea. Ophthalmology. 2006;113(11):1927-35.

[35] Laschke MW, Harder Y, Amon M, Martin I, Farhadi J, Ring A, et al. Angiogenesis in tissue engineering: breathing life into constructed tissue substitutes. Tissue Eng. 2006;12(8):2093-104.

[36] Koizumi N, Inatomi T, Quantock AJ, Fullwood NJ, Dota A, Kinoshita S. Amniotic membrane as a substrate for cultivating limbal corneal epithelial cells for autologous transplantation in rabbits. Cornea. 2000;19(1):65-71.

[37] Yates CC, Hebda P, Wells A. Skin wound healing and scarring: fetal wounds and regenerative restitution. Birth Defects Res C Embryo Today. 2012;96(4):325-33.

[38] Solomon A, Wajngarten M, Alviano F, Anteby I, Elchalal U, Pe'er J, et al. Suppression of inflammatory and fibrotic responses in allergic inflammation by the amniotic membrane stromal matrix. Clinical \& Experimental Allergy 2005; 35(7): 941-948.

[39] Akle CA, Adinolfi M, Welsh KI, Leibowitz S, McColl I. Immunogenicity of human amniotic epithelial cells after transplantation into volunteers. Lancet.1981;2(8254):1003-5.

[40] Kesting MR, Loeffelbein DJ, Steinstraesser L, Muecke T, Demtroeder C, Sommerer F, et al. Cryopreserved human amniotic membrane for soft tissue repair in rats. Ann Plast Surg. 2008;60(6):684-91.

[41] Bhowmik DM, Dinda AK, Mahanta P, Agarwal SK. The evolution of the Banff classification schema for diagnosing renal allograft rejection and its implications for clinicians. Indian J Nephrol. 2010;20(1):2-8. 